\title{
Preparation of Au nano-tips for in-situ Investigation of Early- Age Localized Corrosion of Three Metals by Scanning Electrochemical Microscope
}

\author{
Huan Hao ${ }^{1}$, Chaodi $\mathrm{Xu}^{1}$, Yongxin $\mathrm{Li}^{1,3, *}$,Emily Jackson ${ }^{3}$, Xianming Shi ${ }^{2, *}$ \\ ${ }^{1}$ College of Chemistry and Materials Science, Anhui Normal University, Wuhu 241000, China \\ ${ }^{2}$ Laboratory of Corrosion Science \& Electrochemical Engineering, Department of Civil and \\ Environmental Engineering, Washington State University, Pullman, WA 99164-2910; \\ ${ }^{3}$ Corrosion and Sustainable Infrastructure Laboratory, Western Transportation Institute, PO Box \\ 174250, College of Engineering, Montana State University, Bozeman, MT 59717-4250, USA \\ *E-mail: yongli@mail.ahnu.edu.cn, xianming.shi@wsu.edu
}

doi: $10.20964 / 2017.05 .54$

Received: 14 February 2017 / Accepted: 28 March 2017 / Published: 12 April 2017

In this work, scanning electrochemical microscopy (SECM) was employed for corrosion studies of carbon steel, stainless steel and aluminum alloy in a neutral chloride solution. The SECM Au tips at nano-scale size were prepared by laser-assisted pulling method and characterized by scanning electron microscope (SEM) and electrochemical method. In the SECM test, the $\mathrm{I}^{-} / \mathrm{I}_{3}{ }^{-}$redox couple was used as a mediator for mapping the temporal and spatial evolutions of tip current on each metallic substrate with or without a scratched nanocomposite coating. The results reveal that it is appropriate to combine the generation-collection (G-C) mode of SECM with the feedback current mode in order to elucidate the possible reaction mechanism and pathways underlying the localized corrosion of the three metals investigated.

Keywords: Stainless steel; carbon steel; aluminum alloy; localized corrosion; scanning electrochemical microscope (SECM)

\section{$\underline{\text { FULL TEXT }}$}

(C) 2017 The Authors. Published by ESG (www.electrochemsci.org). This article is an open access article distributed under the terms and conditions of the Creative Commons Attribution license (http://creativecommons.org/licenses/by/4.0/). 